\title{
Bacterial vaginosis in female facility workers in north-western Tanzania: prevalence and risk factors
}

\author{
K Baisley, ${ }^{1,2}$ J Changalucha, ${ }^{2}$ H A Weiss, ${ }^{1}$ K Mugeye, ${ }^{3}$ D Everett, ${ }^{1,2}$ I Hambleton, ${ }^{1,2}$ \\ P Hay, ${ }^{4}$ D Ross, ${ }^{1}$ C Tanton, ${ }^{1,2}$ T Chirwa, ${ }^{1,2}$ R Hayes, ${ }^{1}$ D Watson-Jones ${ }^{1,3}$
}

${ }^{1}$ London School of Hygiene \&

Tropical Medicine, London, UK;

${ }^{2}$ National Institute for Medical

Research (NIMR), Mwanza,

Tanzania; ${ }^{3}$ African Medical and

Research Foundation (AMREF),

Mwanza, Tanzania; ${ }^{4} \mathrm{St}$

George's Hospital, London, UK

Correspondence to:

Kathy Baisley, Department of Epidemiology \& Population

Health, Keppel Street, London,

WC1E 7HT, UK; kathy.baisley@

Ishtm.ac.uk

Accepted 15 May 2009

Published Online First

26 May 2009

\section{ABSTRACT}

Objectives: To determine prevalence of, and risk factors for, bacterial vaginosis (BV) among herpes simplex virus (HSV) 2 seropositive Tanzanian women at enrolment into a randomised, placebo-controlled trial of HSV suppressive treatment

Methods: 1305 HSV-2 seropositive women aged 16-35 years working in bars, guesthouses and similar facilities were interviewed, examined and tested for HIV, syphilis, Neisseria gonorrhoeae, Chlamydia trachomatis, BV, candidiasis and trichomoniasis. Factors associated with BV were analysed using logistic regression to estimate odds ratios and 95\% confidence intervals.

Results: BV prevalence was 62.9\%; prevalence of Nugent score 9-10 was $16.1 \%$. Independent risk factors for BV were work facility type, fewer dependents, increasing alcohol consumption, sex in the last week (adjusted OR 2.03; 95\% Cl 1.57 to 2.62), using cloths or cotton wool for menstrual hygiene, HIV (adjusted OR 1.41; 95\% Cl 1.09 to 1.83) and Trichomonas vaginalis infection. There was no association between BV and the frequency or method of vaginal cleansing. However, BV was less prevalent among women who reported inserting substances to dry the vagina for sex (adjusted OR 0.44; 95\% Cl 0.25 to 0.75$)$.

Conclusion: BV was extremely prevalent among our study population of HSV-2 positive female facility workers in North-western Tanzania. Although recent sex was associated with increased BV prevalence, vaginal drying was associated with lower BV prevalence. Further studies of the effects of specific practices on vaginal flora are warranted.

Bacterial vaginosis (BV) is one of the most common vaginal infections worldwide. It is characterised by vaginal flora changes, including a decrease in lactobacilli, particularly those that produce hydrogen peroxide, and an increase in anaerobic and facultative anaerobic bacteria. BV has been associated with a variety of adverse health outcomes, including preterm delivery, ${ }^{1}$ intrauterine infection, ${ }^{1}$ pelvic inflammatory disease (PID) ${ }^{2}$ and other gynaecological complications. ${ }^{3}$

BV may also increase susceptibility to HIV and other sexually transmitted infections (STIs), ${ }^{4-6}$ and in prospective studies BV has been associated with the acquisition of HIV and herpes simplex virus (HSV) type 2. ${ }^{7-11}$ BV may also facilitate HIV and HSV-2 transmission by increasing the frequency of genital shedding of the virus. ${ }^{12}$

The aetiology of BV remains poorly understood, although sexual activity and vaginal hygiene practices have been associated with BV. ${ }^{43-16}$ Reproductive hormones are also thought to play a role in the regulation of vaginal flora. ${ }^{17}{ }^{18}$ In subSaharan Africa, the prevalence of BV is very high, ranging from $30-51 \%$ in community based studies. ${ }^{610} \mathrm{~A}$ high prevalence has also been reported among African-American women with estimates of up to $50 \%$ in population-based surveys. ${ }^{19}$ The reasons for this are unclear. Prevention of $\mathrm{BV}$, and any impact that this might have on reducing the risk of HIV acquisition, will depend in part on identification of risk factors for BV that are susceptible to interventions.

We report on the factors associated with BV prevalence at baseline in a cohort of women at high risk of STI working in bars, guesthouses and similar facilities in Tanzania. These women were enrolled into a trial of the effect of HSV-2 suppressive treatment on HIV incidence, and on genital HIV and HSV-2 viral shedding in women who are HIV positive.

\section{MATERIALS AND METHODS}

\section{Study population}

A randomised, double-blind, placebo-controlled trial of acyclovir $400 \mathrm{mg}$ twice daily suppressive treatment was conducted in women HSV-2 seropositive in the Lake Victoria region of Tanzania. In total, 1305 women aged 16-35 years working in bars, guesthouses and similar facilities were enrolled in three phases from January 2004 to May 2006. Trial procedures have been described previously. ${ }^{20}$ Screening, enrolment and 3-monthly follow-up visits were conducted at mobile clinics established in 19 communities in high HIVtransmission areas. Women were followed for 1230 months depending on phase of enrolment.

At screening, after informed consent, participants were tested for antibodies to HSV-2 and HIV, and interviewed about sociodemographic details, sexual behaviour and intravaginal practices (IVP). Eligible women were given an appointment to attend the mobile clinic 8-12 weeks later; women were asked to avoid vaginal cleansing before attending the visit. To be eligible, women had to be HSV-2 seropositive, have no history of epilepsy, able to give informed consent, not planning to move out of the study site, not breastfeeding and not pregnant or planning pregnancy during follow-up.

At enrolment, participants were tested for pregnancy and were asked about recent sexual behaviour and IVP. Women were examined for symptoms of reproductive tract infections (RTI), and blood and genital samples were collected. Participants were offered syndromic management online under the BMJ Journals unlocked scheme, see http:// sti.bmj.com/info/unlocked.dtl 
for any RTI diagnosed at enrolment, risk reduction counselling, family planning and condoms.

All women, including those ineligible to enrol, were offered free HIV voluntary counselling and testing, with onward referral to the nearest centre providing HIV care, including anti-retroviral treatment where appropriate.

\section{Laboratory methods}

Screening sera were tested for HSV-2 using a type-specific IgG ELISA (Kalon Biologicals, Guildford, Surrey, UK). Screening and enrolment sera were tested for HIV by dual ELISA (Murex HIV $\mathrm{Ag} / \mathrm{Ab}$ Combination ELISA, Murex Biotech, Dartford, UK; UniFormII Ag/Ab micro ELISA system, bioMérieux, Basingstoke, UK). Repeatedly discordant samples were tested by HIV-1 p24 Ag EIA (Biorad Genetic Systems, California, USA) and line immunoassay (INNO-LIA HIV I/II, Innogenetics, Gent, Belgium), as described previously. ${ }^{20}$ Enrolment samples were tested for syphilis by the rapid plasma reagin (RPR) test (Omega Diagnostics, Alva, Scotland, UK) and Treponema pallidum particle agglutination (TPPA) assay (Fujirebio Inc, Tokyo, Japan), and by fluorescent treponemal antibody assay (TrepoSpot IF, bioMérieux, Maray-l'Etoile, France) if RPR positive and TPPA negative.

For BV, vaginal smears were heat-fixed and Gram-stained then examined by light microscopy by a single reader and scored using the Nugent criteria. ${ }^{21}$ External quality control of a random sample of $10 \%$ of slides was performed by an external reader (PH). Trichomonas vaginalis was diagnosed by wet preparation and culture (InPouch TV, BioMed Diagnostics, San Jose, California, USA). Wet preparations were examined by light microscopy for Candida albicans spores and hyphae. Chlamydia trachomatis and Neisseria gonorrhoeae were diagnosed by the AmplicorCT/NG PCR assay (Roche Diagnostics Systems, Branchburg, New Jersey, USA). N gonorrhoeae PCR-positive samples were retested in duplicate and classified using a "twoout-of-three" strategy, and an optical density $\geqslant 2$ was used as the cut-off for positive rather than the manufacturer's recommended value of $\geqslant 0.2$.

Cervico-vaginal lavage (CVL) from all HIV positive women were tested for HIV-1 RNA and HSV DNA by real-time PCR using the ABI-7300 system (Applied Biosystems, Courtabeouf, France) and manual nucleic acid extraction (Nuclisens miniMAG bioMérieux, Marcy l'Etoile, France). In addition, CVL from a random sample of 449 HIV negative women were tested for HSV using the same method.

\section{Statistical methods}

Risk factors for BV were analysed using odds ratios (OR) and 95\% confidence intervals (CI) obtained by logistic regression. Normal and intermediate flora categories (Nugent score 0-6) were combined to form the category "absence of BV". Unclassifiable slides containing blood, mucus and/or pus were excluded.

Potential determinants of BV infection were considered using a conceptual framework ${ }^{22}$ with four groups: socio-economic factors, sexual behavioural factors, IVP and menstruation, and biological factors. Age, considered an a priori confounder, was included in all multivariate models. An initial model included socio-economic factors adjusted for age. Factors whose association reached statistical significance at $p<0.1$ were included in a multivariate model and those that remained independently associated with BV $(p<0.1)$ were retained. The association between each determinant in the sexual behaviour group was assessed by adding the single determinant into the multivariate socio-economic model. Sexual behavioural factors whose association reached significance at $p<0.1$ were included in a multivariate model; those which remained significantly associated with BV $(p<0.1)$ were retained. Associations with factors in the IVP group and in the biological group were assessed in the same way. The final model was reached by excluding factors one at a time until all remaining factors were significant at the $\mathrm{p}<0.05$ level.

\section{RESULTS}

\section{Study population}

Results at screening have been described previously. ${ }^{20}$ In total, 1305 HSV-2 seropositive women were enrolled. Excluding 22 women with unclassifiable vaginal smears, $807(62.9 \%)$ women had BV, 287 (22.4\%) had intermediate changes on Nugent score and $189(14.7 \%)$ had normal flora. Among women with BV, 207 $(25.7 \%)$ had a Nugent score of 9-10.

Overall, $37.1 \%$ of women were HIV seropositive, $13.8 \%$ had evidence of active syphilis, $5.3 \%$ had gonorrhoea, $7.0 \%$ had C trachomatis and $30.3 \%$ had trichomoniasis. HSV genital shedding was detected in $34(7.6 \%)$ HIV negative and 70 (14.5\%) HIV positive women. Among HIV seropositive women, $52.6 \%$ had detectable HIV shedding.

At least one symptom of a RTI was reported by $40.3 \%$ of women. There was no association between any reported clinical symptom and BV prevalence, and $60.7 \%$ of women with BV claimed to be asymptomatic. On examination, women with BV were more likely to have a diagnosis of vaginal discharge syndrome (OR 1.24; $95 \%$ CI 0.99 to 1.57).

\section{Socio-economic factors and association with BV}

The mean age of participants was 27.6 years (SD 4.9); $54 \%$ were divorced, widowed or separated, and $86 \%$ had at least one child. About half (51\%) were local food handlers and $16 \%$ were bar workers. Over half $(53 \%)$ reported drinking alcohol each week. BV was most prevalent in younger women, with $71.8 \%$ of those aged 16-19 years having BV compared with $60.9 \%$ of those aged over 25 years. Prevalence was highest among bar workers and guesthouse workers $(71.0 \%$ and $73.2 \%$, respectively, compared with $59.3 \%$ of local food handlers; table 1). A multivariate model of socio-economic factors adjusted for age showed that type of facility and decreasing number of dependents were independently associated with BV.

\section{Association of BV with sexual and other behavioural factors}

The majority of women $(71 \%)$ reported fewer than 10 lifetime partners and 54\% reported only 1 partner in the past 3 months. Most participants (64\%) reported never or rarely using condoms and $38 \%$ reported having had sex in exchange for money or gifts in the past 3 months. At enrolment, 30\% were using hormonal contraception; among those, $62 \%$ used injectable depotmedroxyprogesterone acetate (DMPA).

On univariate analysis, BV was significantly associated with a number of sexual risk factors, including younger sexual debut, increasing partners in the past 3 months, increasing condom use, paid sex in the past 3 months and sex in the past week (table 1). After adjusting for age and socio-economic factors, only younger age at first sex, increasing alcohol consumption and recent sex remained independently associated with BV. There was some evidence of an inverse association between BV and hormonal contraception (adjusted OR 0.80; 95\% CI 0.62 to 1.04). 
Table 1 Association of socio-economic and behavioural factors with bacterial vaginosis (BV) infection

\begin{tabular}{|c|c|c|c|}
\hline Factor & BV prevalence n/N (\%) & Univariate OR (95\% CI) & Adjusted $\mathrm{OR}^{*}(95 \% \mathrm{CI})$ \\
\hline \multicolumn{4}{|l|}{ Socio-economic factors } \\
\hline Age (years) & & $p=0.02$ & $p=0.36$ \\
\hline 16-19 & $51 / 71(71.8 \%)$ & 1 & 1 \\
\hline $20-24$ & $191 / 285(67.0 \%)$ & $0.80(0.45$ to 1.41$)$ & 0.94 (0.51 to 1.73 ) \\
\hline $25-29$ & $259 / 418(62.0 \%)$ & $0.64(0.37$ to 1.11$)$ & $0.76(0.42$ to 1.40$)$ \\
\hline $30-35$ & $306 / 509(60.1 \%)$ & 0.59 (0.34 to 1.02$)$ & $0.81(0.44$ to 1.49$)$ \\
\hline Marital status & & $p=0.07$ & $p=0.58$ \\
\hline Married/living with partner & 188/324 (58.0\%) & 1 & 1 \\
\hline Divorced/separated/widow & $441 / 693(63.6 \%)$ & $1.27(0.97$ to 1.66$)$ & $1.16(0.87$ to 1.55$)$ \\
\hline Unmarried & 178/266 (66.9\%) & 1.46 (1.04 to 2.05$)$ & $1.17(0.78$ to 1.75$)$ \\
\hline Facility type & & $p=0.002$ & $p=0.07$ \\
\hline Local food handler & $389 / 656$ (59.3\%) & 1 & 1 \\
\hline Restaurant/café/grocery & $116 / 196(59.2 \%)$ & $1.00(0.72,1.38)$ & $0.87(0.62,1.23)$ \\
\hline Guesthouse & $101 / 138(73.2 \%)$ & 1.87 (1.25 to 2.82$)$ & 1.65 (1.08 to 2.52$)$ \\
\hline Local brew seller & $59 / 93(63.4 \%)$ & $1.19(0.76$ to 1.87$)$ & $0.96(0.59$ to 1.56$)$ \\
\hline Bar & $142 / 200(71.0 \%)$ & 1.68 (1.19 to 2.37$)$ & 1.25 (0.86 to 1.83$)$ \\
\hline Education & & $p=0.82$ & $p=0.42$ \\
\hline Primary or above & $570 / 909(62.7 \%)$ & 1 & 1 \\
\hline Less than primary & 237/374 (63.4\%) & $1.03(0.80$ to 1.32$)$ & $0.89(0.68$ to 1.18$)$ \\
\hline Literacy & & $p=0.09$ & $p=0.28$ \\
\hline Yes & 608/986 (61.7\%) & 1 & 1 \\
\hline No & 199/297 (67.0\%) & 1.26 (0.96 to 1.66$)$ & 1.18 (0.87 to 1.58$)$ \\
\hline Number of dependents $\dagger$ & & $\mathrm{p}<0.001$ & $p=0.003$ \\
\hline$\geqslant 2$ & $466 / 785$ (59.4\%) & 1 & 1 \\
\hline 1 & $142 / 224(63.4 \%)$ & $1.19(0.87$ to 1.61$)$ & $1.14(0.82$ to 1.59$)$ \\
\hline None & 199/274 (72.6\%) & $1.82(1.34$ to 2.46$)$ & $1.68(1.20$ to 2.34$)$ \\
\hline \multicolumn{4}{|l|}{ Behavioural factors } \\
\hline Number of drinks per week & & $\mathrm{p}<0.001$ & $p=0.001$ \\
\hline 0 & $347 / 602(57.6 \%)$ & 1 & 1 \\
\hline $1-4$ & $192 / 299(64.2 \%)$ & $1.32(0.99$ to 1.76$)$ & $1.33(0.98$ to 1.81$)$ \\
\hline $5-9$ & $90 / 137(65.7 \%)$ & $1.41(0.95$ to 2.07$)$ & $1.47(0.97$ to 2.22$)$ \\
\hline$\geqslant 10$ & $178 / 245(72.7 \%)$ & $1.95(1.41$ to 2.70$)$ & 1.75 (1.21 to 2.51$)$ \\
\hline Age at first sex & & $p=0.001$ & $p=0.009$ \\
\hline$\geqslant 18 \mathrm{y}$ & 213/368 (57.9\%) & 1 & 1 \\
\hline $16-17$ y & $276 / 448(61.6 \%)$ & $1.17(0.88$ to 1.55$)$ & $1.11(0.83$ to 1.49$)$ \\
\hline $14-15 y$ & $246 / 375(65.6 \%)$ & 1.39 (1.03 to 1.87$)$ & $1.28(0.94$ to 1.75$)$ \\
\hline$<14$ y & $63 / 82(76.8 \%)$ & $2.41(1.39$ to 4.20$)$ & 2.15 (1.21 to 3.81$)$ \\
\hline No. partners in last 3 months & & $\mathrm{p}<0.001$ & $p=0.59$ \\
\hline 0 & $29 / 63(46.0 \%)$ & 1 & 1 \\
\hline 1 & $413 / 690(59.9 \%)$ & 1.75 (1.04 to 2.94$)$ & 1.16 (0.66 to 2.05$)$ \\
\hline 2 & $210 / 323(65.0 \%)$ & 2.18 (1.26 to 3.76$)$ & $1.28(0.70$ to 2.34$)$ \\
\hline$\geqslant 3$ & 155/207 (74.9\%) & 3.49 (1.94 to 6.28$)$ & 1.47 (0.75 to 2.85$)$ \\
\hline Condom use: & & $p=0.007$ & $p=0.59$ \\
\hline Never & $132 / 244(54.1 \%)$ & 1 & 1 \\
\hline Rarely/sometimes & $359 / 570(63.0 \%)$ & $1.44(1.07$ to 1.96$)$ & $1.15(0.83$ to 1.60$)$ \\
\hline Often & $143 / 209(68.4 \%)$ & $1.84(1.25$ to 2.70$)$ & $1.34(0.87$ to 2.05$)$ \\
\hline Always & $172 / 259(66.4 \%)$ & 1.68 (1.17 to 2.41$)$ & $1.22(0.82$ to 1.83$)$ \\
\hline $\begin{array}{l}\text { Sex in exchange for money or } \\
\text { in past } 3 \text { months }\end{array}$ & & $\mathrm{p}<0.001$ & $p=0.20$ \\
\hline No & $464 / 790(58.7 \%)$ & 1 & 1 \\
\hline Yes & $343 / 493(69.6 \%)$ & 1.61 (1.27 to 2.04$)$ & $1.19(0.91$ to 1.54$)$ \\
\hline Hormonal contraception & & $p=0.009$ & $p=0.09$ \\
\hline No & $587 / 900(65.2 \%)$ & 1 & 1 \\
\hline Yes & $220 / 383(57.4 \%)$ & 0.72 (0.56 to 0.92$)$ & 0.80 (0.62 to 1.04$)$ \\
\hline Sex in past 7 days & & $\mathrm{p}<0.001$ & $\mathrm{p}<0.001$ \\
\hline No & 200/393 (50.9\%) & 1 & 1 \\
\hline Yes & $607 / 890(68.2 \%)$ & 2.07 (1.62 to 2.64$)$ & 1.95 (1.52 to 2.50$)$ \\
\hline
\end{tabular}

*Adjusted for age, facility type, number of dependents, number of drinks per week, age at first sex, hormonal contraception and sex in the past 7 days; †number of adults and children for whom respondent is contributing to their food and shelter; $\$$ data for age of first sex are missing for 10 women who could not remember. Data for condom use are missing for 1 woman.

\section{Association of BV with intravaginal practices}

Vaginal cleansing was reported by $65 \%$ of women of whom $99 \%$ reported hygiene to be the primary reason for cleansing and $90 \%$ used soap and water only. The mean cleansing frequency was 2.6 times/day (range 1-7). Using vaginal lubricants, such as petroleum jelly, during sex (wet sex) was reported by $10 \%$ of 
Table 2 Association of intravaginal practices (IVP) and biological factors with bacterial vaginosis (BV) infection

\begin{tabular}{|c|c|c|c|}
\hline Factor & BV prevalence $\mathrm{n} / \mathrm{N}(\%)$ & Univariate $\mathrm{OR}(95 \% \mathrm{Cl})$ & Adjusted $\mathrm{OR}^{*}(95 \% \mathrm{Cl})$ \\
\hline \multicolumn{4}{|l|}{ Intravaginal practices } \\
\hline Vaginal cleansing $\dagger$ & & $p=0.79 ; p$ trend $=0.34$ & $p=0.36 ; p$ trend $=0.10$ \\
\hline Does not cleanse & $292 / 451(64.7 \%)$ & 1 & 1 \\
\hline Once daily & $47 / 74(63.5 \%)$ & 0.95 (0.57 to 1.58$)$ & 0.95 (0.56 to 1.62$)$ \\
\hline Twice daily & $174 / 282(61.7 \%)$ & 0.88 (0.64 to 1.19$)$ & 0.78 (0.56 to 1.08$)$ \\
\hline$\geqslant 3$ times/day & 293/473 (61.9\%) & $0.89(0.68$ to 1.16$)$ & 0.80 (0.60 to 1.07$)$ \\
\hline Usual method of cleansing & & $p=0.39$ & $p=0.20$ \\
\hline Does not cleanse & $292 / 451(64.7 \%)$ & 1 & 1 \\
\hline Water only & $86 / 142(60.6 \%)$ & $0.84(0.57$ to 1.23$)$ & 0.78 (0.52 to 1.18 ) \\
\hline Soap \& water & $368 / 600(61.3 \%)$ & $0.86(0.67$ to 1.11$)$ & 0.78 (0.60 to 1.02$)$ \\
\hline Other products & $60 / 87(69.0 \%)$ & 1.21 (0.74 to 1.98$)$ & 1.11 (0.66 to 1.87$)$ \\
\hline Insert substances for wet sex† & & $p=0.23$ & $p=0.99$ \\
\hline No & $722 / 1158(62.3 \%)$ & 1 & 1 \\
\hline Yes & $84 / 124$ (67.7\%) & 1.27 (0.85 to 1.88$)$ & 1.00 (0.66 to 1.52$)$ \\
\hline Insert substances for dry sex† & & $p=0.008$ & $p=0.004$ \\
\hline No & 777/1220 (63.7\%) & 1 & 1 \\
\hline Yes & $29 / 62(46.8 \%)$ & $0.50(0.30$ to 0.84$)$ & $0.45(0.26$ to 0.78$)$ \\
\hline Any IVP in last $24 \mathrm{~h} \hbar$ & & $p=0.81 ; p$ trend $=0.81$ & $\mathrm{p}=0.89 ; \mathrm{p}$ trend $=0.99$ \\
\hline No & $254 / 413(61.5 \%)$ & 1 & 1 \\
\hline 13-24 h ago & $149 / 230(64.8 \%)$ & $1.15(0.82$ to 1.61$)$ & $1.05(0.74$ to 1.49$)$ \\
\hline $7-12 \mathrm{~h}$ ago & $164 / 255(64.3 \%)$ & $1.13(0.82$ to 1.56$)$ & $1.12(0.80$ to 1.57$)$ \\
\hline$\leqslant 6 \mathrm{~h}$ ago & $240 / 385(62.3 \%)$ & 1.04 (0.78 to 1.38$)$ & 0.98 (0.73 to 1.33$)$ \\
\hline Menstrual hygiene $\dagger$ & & $p=0.05$ & $p=0.02$ \\
\hline Sanitary pads & 135/229 (59.0\%) & 1 & 1 \\
\hline Cloths/underwear/sponges & $623 / 988(63.1 \%)$ & 1.19 (0.89 to 1.59$)$ & $1.34(0.97$ to 1.85$)$ \\
\hline Cotton wool/toilet paper & $39 / 51(76.5 \%)$ & 2.26 (1.13 to 4.55$)$ & 2.53 (1.23 to 5.24$)$ \\
\hline Last menstrual period $\dagger$ & & $p=0.38$ & $p=0.40$ \\
\hline$<7$ days & $216 / 350(61.7 \%)$ & 1 & 1 \\
\hline $7-13$ days & $197 / 296(66.6 \%)$ & 1.23 (0.89 to 1.71$)$ & 1.23 (0.88 to 1.74$)$ \\
\hline$\geqslant 14$ days & $382 / 612(62.4 \%)$ & 1.03 (0.79 to 1.35 ) & 1.02 (0.77 to 1.36$)$ \\
\hline \multicolumn{4}{|l|}{ Biological factors } \\
\hline HIV & & $\mathrm{p}<0.001$ & $p=0.002$ \\
\hline No & $483 / 813(59.4 \%)$ & 1 & 1 \\
\hline Yes & $324 / 470(68.9 \%)$ & $1.52(1.19$ to 1.93$)$ & 1.49 (1.16 to 1.92$)$ \\
\hline Trichomonas vaginalis $\dagger$ & & $\mathrm{p}<0.001$ & $p=0.002$ \\
\hline No & $530 / 889(59.6 \%)$ & 1 & 1 \\
\hline Yes & $274 / 390(70.3 \%)$ & 1.60 (1.24 to 2.06$)$ & 1.54 (1.17 to 2.01$)$ \\
\hline Neisseria gonorrhoeae $\dagger$ & & $p=0.13$ & $p=0.60$ \\
\hline No & 758/1215 (62.4\%) & 1 & 1 \\
\hline Yes & $48 / 67$ (71.6\%) & 1.52 (0.88 to 2.62$)$ & 1.16 (0.65 to 2.07$)$ \\
\hline Chlamydia trachomatis $\dagger$ & & $p=0.37$ & $p=0.11$ \\
\hline No & $754 / 1193(63.2 \%)$ & 1 & 1 \\
\hline Yes & $52 / 89(58.4 \%)$ & $0.82(0.53$ to 1.27$)$ & $0.69(0.44$ to 1.08$)$ \\
\hline Candidiasis $\uparrow$ & & $p=0.61$ & $\mathrm{p}=0.59$ \\
\hline No & $718 / 1145(62.7 \%)$ & 1 & 1 \\
\hline Yes & $87 / 134$ (64.9\%) & $1.10(0.76$ to 1.60$)$ & $1.12(0.75$ to 1.65$)$ \\
\hline HIV genital shedding§ & & $p=0.14$ & $p=0.20$ \\
\hline No & $161 / 223(72.2 \%)$ & 1 & 1 \\
\hline Yes & $162 / 246(65.9 \%)$ & $0.74(0.50$ to 1.10$)$ & 0.76 (0.50 to 1.15$)$ \\
\hline HSV-2 genital shedding & & $p=0.98$ & $p=0.77$ \\
\hline No & $513 / 811(63.3 \%)$ & 1 & 1 \\
\hline Yes & 65/103 (63.1\%) & $0.99(0.65$ to 1.52$)$ & $0.93(0.60$ to 1.46$)$ \\
\hline
\end{tabular}

*Adjusted for age, facility type, number of dependents, number of drinks per week, age at first sex, hormonal contraception and sex in the past 7 days; $†$ data for vaginal cleansing are missing for 3 women. Data for inserting substances for sex are missing for 1 woman. Data for menstrual hygiene are missing for 15 women. Date of last menstrual period could not be remembered by 25 women. Results for Neisseria gonorrhoeae and Chlamydia trachomatis missing for 1 woman. Results for Trichomonas vaginalis and candidiasis missing for 4 women; †cleansing vagina or inserting substances for sex; §among 469 women HIV positive; $\uparrow$ among 914 women (445 HIV negative and 469 HIV positive).

women. Only $5 \%$ reported inserting substances such as lemon or caustic soda to reduce lubrication during sex (dry sex). Although asked to avoid IVP before the clinic visit, $68 \%$ of women reported cleansing or inserting substances for sex in the previous 24 hours. Mean time since last IVP was 9.3 hours (range 1-24) for cleansing and 10.6 hours (4-24) for other IVP. Most women (78\%) reported using cloths for menstrual protection; $4 \%$ reported using cotton wool.

In the univariate analysis, BV was not associated with frequency or timing of vaginal cleansing nor the methods used 
Table 3 Final multivariate model for factors associated with bacterial vaginosis (BV) infection

\begin{tabular}{|c|c|c|}
\hline & BV prevalence $\mathrm{n} / \mathrm{N}(\%)$ & Adjusted $0 \mathrm{R}^{*}(95 \% \mathrm{CI})$ \\
\hline Age (years) & & $p=0.23$ \\
\hline $16-19$ & $51 / 71(71.8 \%)$ & 1 \\
\hline $20-24$ & $191 / 285(67.0 \%)$ & $0.87(0.48$ to 1.60$)$ \\
\hline $25-29$ & $259 / 418(62.0 \%)$ & $0.66(0.37$ to 1.20$)$ \\
\hline $30-35$ & $306 / 509$ (60.1\%) & $0.73(0.40$ to 1.33$)$ \\
\hline Facility type & & $p=0.03$ \\
\hline Local food handler & $389 / 656(59.3 \%)$ & 1 \\
\hline Restaurant/café/grocery & $116 / 196(59.2 \%)$ & $0.90(0.64$ to 1.28$)$ \\
\hline Guesthouse & 101/138 (73.2\%) & $1.82(1.18$ to 2.81$)$ \\
\hline Local brew seller & $59 / 93(63.4 \%)$ & 0.92 (0.56 to 1.51$)$ \\
\hline Bar & $142 / 200(71.0 \%)$ & $1.26(0.85$ to 1.86$)$ \\
\hline Number of dependents & & $p=0.001$ \\
\hline$\geqslant 2$ & $466 / 785(59.4 \%)$ & 1 \\
\hline 1 & $142 / 224(63.4 \%)$ & $1.15(0.82$ to 1.60$)$ \\
\hline None & 199/274 (72.6\%) & 1.75 (1.25 to 2.44$)$ \\
\hline Number of drinks per week & & $p=0.002$ \\
\hline 0 & $347 / 602(57.6 \%)$ & 1 \\
\hline $1-4$ & $192 / 299(64.2 \%)$ & $1.36(1.00$ to 1.85$)$ \\
\hline $5-9$ & $90 / 137(65.7 \%)$ & $1.44(0.94$ to 2.19$)$ \\
\hline$\geqslant 10$ & $178 / 245(72.7 \%)$ & 1.76 (1.22 to 2.55$)$ \\
\hline Sex in past 7 days & & $\mathrm{p}<0.001$ \\
\hline No & $200 / 393(50.9 \%)$ & 1 \\
\hline Yes & $607 / 890(68.2 \%)$ & $2.03(1.57$ to 2.62$)$ \\
\hline Inserting substances for dry sex $\dagger$ & & $p=0.003$ \\
\hline No & $777 / 1220(63.7 \%)$ & 1 \\
\hline Yes & $29 / 62(46.8 \%)$ & $0.44(0.25,0.75)$ \\
\hline Menstrual hygiene $\dagger$ & & $p=0.02$ \\
\hline Sanitary pads & 135/229 (59.0\%) & 1 \\
\hline Cloths/underwear/sponges & $623 / 988(63.1 \%)$ & $1.42(1.02$ to 1.95$)$ \\
\hline Cotton wool/toilet paper & $39 / 51$ (76.5\%) & 2.52 (1.21 to 5.25$)$ \\
\hline HIV & & $\mathrm{p}=0.008$ \\
\hline No & $483 / 813(59.4 \%)$ & 1 \\
\hline Yes & $324 / 470(68.9 \%)$ & $1.41(1.09$ to 1.83$)$ \\
\hline Trichomonas vaginalis $\dagger$ & & $\mathrm{p}<0.001$ \\
\hline No & $530 / 889(59.6 \%)$ & 1 \\
\hline Yes & $274 / 390(70.3 \%)$ & 1.59 (1.22 to 2.09$)$ \\
\hline
\end{tabular}

${ }^{*}$ Adjusted for all variables in the table; + data for inserting substances for dry sex are missing for 1 woman. Data for menstrual hygiene are missing for 15 women. Results for Trichomonas vaginalis are missing for 4 women.

(table 2). In a multivariate model of IVP, adjusted for socioeconomic and sexual behavioural factors, BV was significantly lower among women who reported ever inserting substances for dry sex (adjusted OR $0.45 ; 95 \%$ CI 0.26 to 0.78 ), although there was no association between $\mathrm{BV}$ and vaginal drying in the past 24 hours. BV was higher among women using cloths or cotton wool for menstrual hygiene. There was a non-significant trend towards decreased BV prevalence with increased frequency of vaginal cleansing (adjusted $p=0.10$ ), but no evidence of a trend with reported time since last cleansing.

\section{Association of BV with biological factors}

On univariate analysis, BV prevalence was significantly associated with HIV and $T$ vaginalis infection but not with any other STI or with HIV or HSV genital shedding (table 2). After adjusting for socio-economic, behavioural and IVP factors, HIV and $T$ vaginalis remained significantly associated with BV.

\section{Final independent risk factors for BV}

In the final multivariate model, independent risk factors for BV were facility type, having fewer dependents, increasing alcohol consumption, recent sex, using cloths or cotton wool for menstrual hygiene, and prevalent HIV and $T$ vaginalis infection (table 3). BV was inversely associated with ever inserting substances for dry sex. Age was retained in the final model, although it was no longer significantly associated with BV.

\section{DISCUSSION}

We report an extremely high prevalence of $\mathrm{BV}$ among Tanzanian HSV-2 seropositive women working in bars, guesthouses and similar facilities, with $63 \%$ of women having BV. Other studies in similar populations in sub-Saharan Africa have reported BV prevalence between 20 and $50 \%{ }^{568}{ }^{23}{ }^{24}$ The higher BV prevalence observed in our study is likely to reflect the fact that our population was HSV-2 seropositive, since a strong association between BV and HSV-2 has been observed in many studies. ${ }^{5} 23$

We found BV prevalence to be independently associated with sex in the past 7 days. Other studies have found BV to be associated with increased sexual activity in both community based settings and among women at high risk of STI. ${ }^{15} 1623$ However, a prospective study of rural women in The Gambia found no association between sexual behaviour and $\mathrm{BV},{ }^{25}$ and BV has also been detected in sexually inexperienced women. ${ }^{19} \mathrm{~A}$ recent meta-analysis found the epidemiological data to be consistent with BV having a sexual mode of transmission, ${ }^{15}$ but additional factors are likely to contribute to its aetiology.

Vaginal cleansing was common in our study population as reported in a number of African studies. ${ }^{6} 13232627$ IVPs are believed to alter the dominant flora of the vagina and, thus, increase susceptibility to BV. ${ }^{14} 2728$ IVP, particularly douching, has been described as a risk factor for BV in industrialised countries. ${ }^{1428}$ In sub-Saharan Africa, the association between IVP and BV is inconsistent, perhaps reflecting the heterogeneity of the techniques and substances used. In a prospective study of sex workers in Burkino Faso, vaginal cleansing was not associated with BV. ${ }^{23}$ Among family planning clinic attendees in Zimbabwe and Uganda, vaginal cleansing was not associated with BV although vaginal drying was associated with $\mathrm{BV}$ in the univariate analysis. ${ }^{27}$ Interestingly, we found BV prevalence was significantly lower among women who reported inserting drying substances, although that practice was relatively uncommon. Furthermore, we found a suggestion of a trend towards decreasing BV with increasing frequency of vaginal cleansing.

Menstrual hygiene practices have also been suggested as an explanation for the higher prevalence of $\mathrm{BV}$ in sub-Saharan Africa. BV prevalence was higher among women in our study who used cloths or cotton wool than in those who used sanitary pads. However, a study in Uganda found no association between BV and using cloths for menstrual hygiene. ${ }^{26}$ Furthermore, a crossover trial in The Gambia of modern pads and traditional cloths found BV to be slightly more frequent when women used sanitary pads. ${ }^{25}$

Although not statistically significant, we found some evidence of a protective effect of hormonal contraception on BV, which is consistent with other studies. ${ }^{12}{ }^{27}$ The relationship between hormones, contraception and BV is not wellunderstood. Oestrogen increases vaginal epithelial cell activity, resulting in increased glycogen and a more favourable environment for lactobacilli. ${ }^{17}$ However, the prevalence of $\mathrm{BV}$ among post-menopausal women is low despite low oestrogen levels. ${ }^{17}$

We found strong independent associations of BV with HIV and $T$ vaginalis. The association between BV and HIV acquisition has been reported in several prospective studies in sub-Saharan Africa. ${ }^{11} 27$ In a similar cohort in Tanzania, women with BV at baseline had a twofold higher risk of HIV 


\section{Key messages}

- Bacterial vaginosis (BV) prevalence was extremely high in this cohort of HSV-2 positive women.

- Consistent with studies in industrialised countries and Africa, we found strong independent associations of BV with HIV, Trichomonas vaginalis and recent sex.

- Vaginal cleansing was very common in this cohort, but we found no association between BV and the frequency, timing or methods of cleansing.

- BV prevalence was significantly lower among women who reported inserting vaginal drying substances, although that practice was relatively uncommon.

seroconversion than those without $\mathrm{BV} .{ }^{8}$ However, a trial of presumptive STI treatment to reduce HIV acquisition showed a marked decrease in BV without any impact on HIV, ${ }^{29}$ and HIV infection may be associated with increased prevalence and persistence of $\mathrm{BV} .^{24}$

There are several limitations to our analysis. This is a crosssectional analysis and so we cannot determine causality of the observed associations. Residual confounding may have remained when adjusting for self-reported risk factors, especially sexual behaviours, which are difficult to measure accurately. The risk factors for BV that we identified may not be generalisable since the women in our study were at high risk of other RTIs and all were HSV-2 positive. Although women were asked to avoid vaginal cleansing before they attended the clinic many reported cleansing in the past 24 hours, which possibly reduced the accuracy of our diagnosis of BV. However, we found no association between women's reported time of last cleansing and BV. Strengths of our study include a large sample size and the use of an expert microbiology laboratory with external quality control to diagnose BV.

Given the association of BV with HIV acquisition shown in many studies, and the extremely high prevalence of $\mathrm{BV}$ in this and other African populations, a high proportion of HIV infections may be attributable to BV. Further research is warranted on preventable risk factors for BV, including specific vaginal practices that may alter the vaginal flora.

Acknowledgements: We would like to thank the Wellcome Trust, the UK Medical Research Council and the Department for International Development UK for funding the study; Mary Rusizoka, Tim Clayton and the HSV trial team; Mary Louise Shushu, and the laboratory and data staff of the Mwanza National Institute for Medical Research; the administrative staff of AMREF Mwanza; Gerald Baldrey and Geita Gold Mine; Tamara Hurst and Fiona Marquet of the Wellcome Trust Bloomsbury Centre for Clinical Tropical Medicine and Lucy Bradshaw at LSHTM. We are very grateful to the Tanzanian Ministry of Health for permission to conduct and publish this study. We gratefully acknowledge the support of the trial steering committee (A Nunn, F Cowan, S Kapiga, H Mshinda) and the Data Monitoring Committee (D Dunn, H Grosskurth, W Kilama).

Funding: Funding for the study was provided by the Wellcome Trust, the UK Medical Research Council (MRC) and the UK Department for International Development.

Competing interests: None.

Ethics approval: The study protocol was approved by the Medical Research Coordinating Committee of Tanzania and the London School of Hygiene and Tropical Medicine ethics committee (ISRCTN 35385041).

Contributors: KB analysed the data and wrote the first draft of the manuscript; DWJ was principal investigator and supervised the trial; DWJ, RH and HW designed the study; KB, IH and TC supervised the data management; JC, DE and PH supervised the laboratory work; PH performed the external QC; CT and KM supervised fieldwork; all authors commented on drafts of the manuscript and approved the final version.

\section{REFERENCES}

1. Svare JA, Schmidt H, Hansen BB, et al. Bacterial vaginosis in a cohort of Danish pregnant women: prevalence and relationship with preterm delivery, low birthweight and perinatal infections. BJOG 2006;113:1419-25.

2. Paavonen J, Teisala K, Heinonen PK, et al. Microbiological and histopathological findings in acute pelvic inflammatory disease. Br J Obstet Gynaecol 1987;94:454-60.

3. Hillier SL, Kiviat NB, Hawes SE, et al. Role of bacterial vaginosis-associated microorganisms in endometritis. Am J Obstet Gynecol 1996;175:435-41.

4. Bukusi EA, Cohen CR, Meier AS, et al. Bacterial vaginosis: risk factors among Kenyan women and their male partners. Sex Transm Dis 2006;33:361-7.

5. Kaul R, Nagelkerke NJ, Kimani J, et al. Prevalent herpes simplex virus type 2 infection is associated with altered vaginal flora and an increased susceptibility to multiple sexually transmitted infections. J Infect Dis 2007;196:1692-7.

6. Sewankambo $\mathbf{N}$, Gray RH, Wawer MJ, et al. HIV-1 infection associated with abnormal vaginal flora morphology and bacterial vaginosis. Lancet 1997;350:546-50.

7. Cherpes TL, Meyn LA, Krohn MA, et al. Association between acquisition of herpes simplex virus type 2 in women and bacterial vaginosis. Clin Infect Dis 2003;37:31925.

8. Kapiga SH, Sam NE, Bang H, et al. The role of herpes simplex virus type 2 and othe genital infections in the acquisition of HIV-1 among high-risk women in northern Tanzania. J Infect Dis 2007;195:1260-9.

9. Martin HL, Richardson BA, Nyange PM, et al. Vaginal lactobacilli, microbial flora, and risk of human immunodeficiency virus type 1 and sexually transmitted disease acquisition. J Infect Dis 1999;180:1863-8.

10. Myer L, Denny L, Telerant R, et al. Bacterial vaginosis and susceptibility to HIV infection in South African women: a nested case-control study. J Infect Dis 2005:192:1372-80.

11. Taha TE, Hoover DR, Dallabetta GA, et al. Bacterial vaginosis and disturbances of vaginal flora: association with increased acquisition of HIV. Aids 1998;12:1699-706.

12. Cherpes TL, Melan MA, Kant JA, et al. Genital tract shedding of herpes simplex virus type 2 in women: effects of hormonal contraception, bacterial vaginosis, and vaginal group B Streptococcus colonization. Clin Infect Dis 2005;40:1422-8.

13. Hassan WM, Lavreys L, Chohan V, et al. Associations between intravaginal practices and bacterial vaginosis in Kenyan female sex workers without symptoms of vaginal infections. Sex Transm Dis 2007:34:384-8.

14. Ness RB, Hillier SL, Richter HE, et al. Douching in relation to bacterial vaginosis, lactobacilli, and facultative bacteria in the vagina. Obstet Gynecol 2002;100:765.

15. Fethers KA, Fairley CK, Hocking JS, et al. Sexual risk factors and bacterial vaginosis: a systematic review and meta-analysis. Clin Infect Dis 2008;47:1426-35.

16. Cherpes TL, Hillier SL, Meyn LA, et al. A delicate balance: risk factors for acquisition of bacterial vaginosis include sexual activity, absence of hydrogen peroxide-producing lactobacilli, black race, and positive herpes simplex virus type 2 serology. Sex Transm Dis 2008;35:78-83.

17. Hillier SL, Lau RJ. Vaginal microflora in postmenopausal women who have not received estrogen replacement therapy. Clin Infect Dis 1997;25:S123-6.

18. Riggs M, Klebanoff M, Nansel T, et al. Longitudinal association between hormonal contraceptives and bacterial vaginosis in women of reproductive age. Sex Transm Dis 2007:34:954-9.

19. Koumans EH, Sternberg M, Bruce C, et al. The prevalence of bacterial vaginosis in the United States, 2001-2004; associations with symptoms, sexual behaviors, and reproductive health. Sex Transm Dis 2007;34:864-9.

20. Watson-Jones D, Weiss HA, Rusizoka M, et al. Risk factors for herpes simplex virus type 2 and HIV among women at high risk in northwestern Tanzania: preparing for an HSV-2 intervention trial. J Acquir Immune Defic Syndr 2007;46:631-42.

21. Nugent RP, Krohn MA, Hillier SL. Reliability of diagnosing bacterial vaginosis is improved by a standardized method of gram stain interpretation. J Clin Microbiol 1991:29:297-301.

22. Victora CG, Huttly SR, Fuchs SC, et al. The role of conceptual frameworks in epidemiological analysis: a hierarchical approach. Int J Epidemiol 1997;26:224-7.

23. Nagot N, Ouedraogo A, Defer MC, et al. Association between bacterial vaginosis and Herpes simplex virus type-2 infection: implications for HIV acquisition studies. Sex Transm Infect 2007:83:365-8.

24. Riedner G, Hoffmann 0, Rusizoka M, et al. Decline in sexually transmitted infection prevalence and HIV incidence in female barworkers attending prevention and care services in Mbeya Region, Tanzania. Aids 2006;20:609-15.

25. Morison L, Ekpo G, West B, et al. Bacterial vaginosis in relation to menstrual cycle menstrual protection method, and sexual intercourse in rural Gambian women. Sex Transm Infect 2005;81:242-7.

26. Demba $\mathbf{E}$, Morison L, van der Loeff MS, et al. Bacterial vaginosis, vaginal flora patterns and vaginal hygiene practices in patients presenting with vaginal discharge syndrome in The Gambia, West Africa. BMC Infect Dis 2005;5:12.

27. van de Wijgert $\mathbf{J H}$, Morrison CS, Cornelisse PG, et al. Bacterial vaginosis and vaginal yeast, but not vaginal cleansing, increase HIV-1 acquisition in African women. $J$ Acquir Immune Defic Syndr 2008;48:203-10.

28. Myer L, Kuhn L, Stein ZA, et al. Intravaginal practices, bacterial vaginosis, and women's susceptibility to HIV infection: epidemiological evidence and biological mechanisms. Lancet Infect Dis 2005;5:786-94.

29. Gray RH, Wabwire-Mangen F, Kigozi G, et al. Randomized trial of presumptive sexually transmitted disease therapy during pregnancy in Rakai, Uganda. Am J Obstet Gynecol 2001;185:1209-17. 